\title{
ERMi esemekogud ja -analüüs
}

\section{Liisi Jääts}

\section{Sissejuhatus}

Esemed moodustavad inimkultuuri olemusliku osa - raske on nimetada mõnda argielu keskkonda või tegevust, mille juurde ei kuuluks (inimese valmistatud) esemed. Materiaalse kultuuri uurija Björnar Olseni sõnutsi peame me nende olemasolu nii enesestmõistetavaks ja loodame nende käepärasusele sedavõrd pimesi, et märkame neid alles siis, kui need on katki või kadunud (Olsen 2017: 76). Pikka aega käsitleti uurimises esemelist maailma kui vaimsele kultuurile vastanduvat või sellest eraldi seisvat. Tänapäeval võetakse esemeid kultuuri integraalse osana. Nähtus (näiteks ese, dokument, tegevus vm) muutub alles siis uurimisallikaks, kui sellele esitatakse mingeid kindlasuunalisi küsimusi (Kõresaar 2012). Esemed on väärtuslik allikaliik, sest esindavad tükikest mineviku või tänapäeva olustikust, midagi, mida inimesed on valmistanud ja kasutanud. Samas sisaldab esemeuurimine alati tõlgendust. Esemeid uurima hakates mõlguvad uurijal meeles mingid küsimused, teatud uurimisraamistik. Teda mõjutavad kehtivad teadusteooriad, seisukohad selle kohta, mida saab uurida ja peab uurima, samuti varem kirjutatu.

Kultuuriuurija ja museoloog Barbara KirschenblattGimblett on eseme, muuseumi ja uurimistöö suhted kokku võtnud nii: „Etnograafilised esemed [...] on etnograafide loodud esemed. 
Esemed muutuvad etnograafiliseks, kuna etnograafid on need nõnda määratlenud, lahterdanud, oma keskkonnast eemaldanud ja [muuseumisse] viinud.“ (Kirschenblatt-Gimblett 1991: 386) Uurimise allikaks olev ese ei pea siiski tingimata paiknema muuseumikogus. Nüüdisaja argielu uurides võib allikana kasutada ka inimeste valduses olevaid esemeid neid muuseumi toomata. Muuseumikoguga liidetud ese on eemaldatud selle algsest keskkonnast ja taustast ning asetatud täiesti teistsugusesse, muuseumi konteksti. Ese varustatakse lisainformatsiooniga vastavalt muuseumikogude süsteemile. Seega on uurijal tarvis mõelda kolme konteksti peale: praegune muuseumikogude kontekst, eseme kogumise kontekst ja eseme algne kontekst, kus see oli enne muuseumisse toomist (foto 15). Tavaliselt huvitab uurijat just viimane. Ometi on tarvis teadvustada ka ülejäänud kahte, sest eseme kogumisega seotud ning muuseumikogudega liitmise asjaolud mõjutavad seda, kuidas me (kogude) eset tajume.

Foto 15

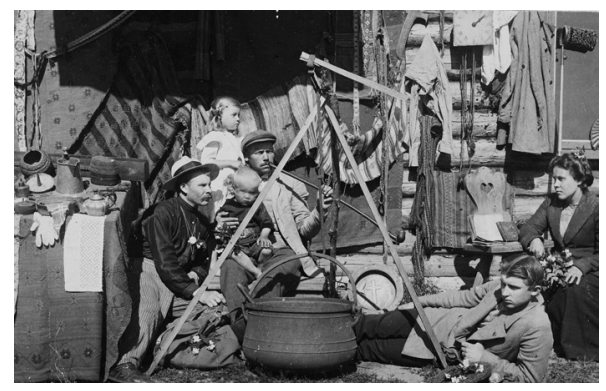

Muuseumikogude esemete allikakriitiline uurimine võtab arvesse kõiki kolme konteksti, püüdes mõista iga eseme puhul, mis on selle tugevused ja nõrkused ja kuidas kajastuvad selles varasemate aastakümnete teadus- ning muuseumitavad. Sõltub uurimisküsimusest, mis aspekt eseme juures uurijale enim huvi pakub ja millist taustinformatsiooni ta juurde vajab.

Artikkel on abiks ERMi esemekogude uurijale. Anname ülevaate, mis printsiipide alusel on esemed ERMi esemekogude vahel jagatud ning millistest teistest kogudest võib saada konkreetse eseme kohta täiendavat teavet (pildina, tekstina). Räägime, kuidas on etnoloogiateaduse teooriad ja meetodid mõjutanud seda, mida muuseumisse kogutakse. Millist informatsiooni on rohkem kui sajandi jooksul toimunud välitöödel esemete kohta kogutud? Millistest sammudest võiks koosneda eseme kui allika uurimine? Kui hästi kajastab muuseumikogu teatava ajaloolise perioodi argielu?

Kindlasti on esemeuurimise ja allikakäsitluse raames vaja analüüsida ka andmebaasi MuIS (www.muis.ee) plusse ja miinuseid 
ning viisi, kuidas sealne informatsiooniesitus mõjutab uurija tööd. Samas on see nii mahukas ja selgepiiriliselt eristuv teema, et väärib eraldi käsitlust ja pole seega siinses artiklis kajastatud.

\section{ERMi esemekogude liigendus}

ERMi esemekogudest annab ülevaate tabel 1.

Tabel 1. ERMi esemekogud

\begin{tabular}{|l|l|l|}
\hline Kogu tähis & Kogu liik & Esemeid \\
\hline A & Eesti alalt ja mujalt maailmast etnilistelt eestlastelt kogutud esemed & $c a 107$ ooo \\
\hline B & Teistelt soome-ugri rahvastelt kogutud esemed & $c a 10$ ooo \\
\hline C & Muudelt (st mitte-soome-ugri) rahvastelt kogutud esemed & $c a 3000$ \\
\hline D & Eesti alalt ja väliseestlastelt kogutud nn kultuuriloolised esemed & $c a 21$ ooo \\
\hline K & Kujutava kunsti esemed & $c a 1500$ \\
\hline PM E & Postimuuseumi esemekogu & $c a 1500$ \\
\hline HM E & Heimtali muuseumi esemekogu & $c a 1600$ \\
\hline TM & Tartumaa muuseumi esemekogu & $c a 4600$ \\
\hline
\end{tabular}

Eesti kogu (A) hõlmab peale etniliste eestlaste (sh eestlaste diasporaa) ka Eesti ala teiste rahvuste esindajate juurest kogutud esemeid, nt rannarootslased, vanausulised ja teised venekeelsed elanikkonna grupid.

Soome-ugri rahvaste kogu (B) sisaldab nende juurest kogutud etnograafilisi esemeid (rahvariided, tööriistad ja elamusisustus).

Võõrrahvaste kogus (C) on etnograafilised esemed, mis ei pärine ei eestlastelt ega teistelt soome-ugri rahvastelt. Sinna kuuluvad peamiselt Siberi, aga ka Hiina, Aafrika ja teiste rahvaste esemed.

Kultuuriloolises kogus (D) on Eesti ala linna- ja mõisakultuuri esemed, samuti need, mis kajastavad inimeste kuuluvust organisatsioonidesse ja nende ametkondlikku tegevust.

ERMi kunstikogu (K) sisaldab peamiselt Tartut ja Tartu ümbruskonna mõisaid kujutavaid graafilisi lehti, jooniseid ja akvarelle, samuti rahvarõivaid ja rahva eluolu puudutavaid töid.

Postimuuseumi esemekogusse (PM E) kuuluvad postiga seonduvad esemed (postikotid, mööbel, telefonid, postkastid, vormiriietus, tembeldusmasinad jne).

Heimtali muuseumi esemekogu (HM E) koosneb tekstiilikunstnik Anu Raua kogutud, põhiosas Mulgimaa, aga ka teiste 
Eesti piirkondade tekstiilinäidistest. Kogu asub Heimtali muuseumis.

Tartumaa muuseumi kogu (TM) on saadud likvideeritud Tartumaa muuseumilt ja see sisaldab peamiselt Tartu maakonnaga seotud materjale. Kuna kogude liitmine ERMi omadega on veel pooleli, ei saa esemekogu suurust täpselt välja tuua.

See jaotus peegeldab ERMi kogude kujunemise ajalugu, muu hulgas aegade jooksul kehtinud kogumis- ja uurimissuundi. Nii näiteks moodustavad lisaks kogule A Eestist pärit ja/või eestlastega seotud esemed ka kogu D. See on kultuurilooliste esemete kogu, kuhu algse muuseumi süstemaatika järgi liigitati linna- ja mõisakultuuriesemed. Heiki Pärdi on kogu A ja D analüüsides sedastanud, et nende loomise ajal 1920. aastatel eeldati, et etnograafilised esemed olid talurahva, st maal elavate inimeste omad ja linnaelanike, haritlaste, aadelkonna jm ühiskonnakihtide vara etnograafia uurimisalasse ei kuulunud. Seega peegeldab Eesti ala esemete jagamine kogu A ja D vahel omaaegset arusaama nii etnograafiast kui ka kultuurist ning ei ole sellisena neutraalne. (Pärdi 1994: 13-15) Kultuuriloolise kogu loomise algusest peale on sinna liigitatud esemeid, mis seostuvad inimeste kuulumisega mitmesugustesse seltsidesse ja ametkondadesse (nt märgid, medalid, vimplid, ametiriietus) või teatud sündmustega (nt laulupeomärgid, ERMi juubelite puhul saadud kingitused teistelt asutustelt ja organisatsioonidelt). Sama lähenemine kehtis kogu nõukogude aja ning on sõnastatud ka tänapäevase D kogu täiendamise põhimõttena (Eesti Rahva Muuseumi kogude korralduse põhimõtted 2015-2019: 19). Kultuuriloolisse kogusse kuulub veel mõisatest (nt Raadi mõisa mööbel D 114) ning linnakodudest pärinev mööbel ja muu tarbevara (nt D 97), mis jõudis muuseumisse 1940. aastate poliitiliste keeriste tagajärjel ja liigitati tollaste arusaamade kohaselt mitteetnograafiliseks. Tänapäevase etnoloogia vaatevinklist, kus selle teadusharu uurimisvaldkond on laienenud talupojakultuurilt kogu argielule, inimestele kui kultuuriloojatele, pole põhjust näha üht kogu etnoloogiliseks uurimistööks sobivamana kui teist. Küll aga annavad kogude komplekteerimise põhimõtted uurija jaoks viiteid, millisest kogust üht või teist eset eelkõige otsida.

Mõistagi kuuluvad Heimtali, Tartumaa või Postimuuseumi kogud allikana eesti kultuuri uurija jaoks samasse ritta koguga A või D. Nende eristamine ERMi kogude süsteemis tuleneb soovist jätta varem iseseisvate muuseumide kogud selgelt eristatavaks.

Alljärgnev puudutab eelkõige A kogu, mis on mahult suurim ning millel on tihedad seosed ERMi etnograafilise arhiivi, foto- ja joonistekoguga (sellest pikemalt allpool). Posti-, Heimtali ja Tartumaa muuseumi kogud, mis on ERMiga liidetud viimase kümmekonna 
aasta jooksul, on säilitanud ka pärast liitmist oma varasema sisemise liigenduse, mis ERMis tavaks olnud süsteemiga ei kattu.

ERMi on esemed jõudnud põhiliselt kolmel viisil:

1. välitöödelt kaasa toodud, st muuseumi algatuse tulemusel (välitööde käigus kogutud esemete kohta vt alaptk „Muuseumi- ja kogumiskontekst“ lk 133-135);

2. eseme omaniku poolt muuseumile pakutud ehk nn passiivse kogumise tulemusel;

3. muudel asjaoludel, nt muuseumide ümberkorraldamise käigus ühest muuseumist teise toodud esemed (nt Tartu kunstimuuseumilt ERMile üle antud), mõne organisatsiooni või ettevõtte tegevuse lõpetamisel (gildid ja tsunftid 1920. aastatel, üliõpilaskorporatsioonid 1940. aastatel, Kommunaar ja Uku) vms.

Muuseumisse vastuvõtmisel saavad ühe välitöö käigus kogutud esemed üksikkollektsiooni ehk kogu numbri, nt kogusse A 58 kuulub 40 eset, mille kogus Voldemar Haas 1920. aastal välitöödel Karula, Hargla, Rõuge ja Tori kihelkonnas. Samamoodi on ühe üksikkollektsiooni numbri alla koondatud rahvakunstimeistrite koondise Uku varade üleandmisel kogudesse vastu võetud esemed (A 851).

Eesti esemete kogus on üks oluline alljaotus: need on esimesed 20 ooo eset, millest muuseumi esemekogud 20. sajandi esimestel aastakümnetel alguse said. Tol ajal ei olnud kogud veel praeguse korra järgi süstematiseeritud (see sai alguse 1920. aastatel), kõigile vastu võetud esemetele anti lihtsalt järjekorranumber. Seega kuuluvad needki Eesti etnograafilise kogu alla, kuid ilma tähiseta A. See on oluline eristus, mis tähistab kogumistöö etappe ja muutumist.

\section{Esemete lisaandmed muuseumis}

Ese üksi ei räägi enda kohta kuigi palju ja seetõttu on kogumise algaegadest saadik talletatud esemete kohta lisainfot, mida leiab muuseumis järgmistest kohtadest:

1. Korjamisraamat ehk kogutud esemete nimistu, kuhu kirjutati välitööde ajal esmane teave: mis ese kelle käest koguti ja kus; kes selle valmistas; kui vana oli ese kogumise hetkel ja lühidalt muu lisainformatsioon nt eseme kasutamise või valmistamise kohta. Korjamisraamatud olid kasutusel aastani 2002.

2. Peakataloog: iga eseme kohta, mis otsustati kogusse vastu võtta, lisati peakataloogi suureformaadilisse köitesse selle kirjeldus. See sisaldas esemele antud inventarinumbrit (nt A 58:3), uuesti kõiki 
korjamisraamatusse kantud andmeid, eseme kirjeldust koos mõõtudega ja selle füüsilist seisukorda. Lisaks on peakataloogis iga üksikkogu alguses sissekanne selle päritolu kohta, nt mis aastal ja mis piirkonnas korraldatud välitöödel kogutud esemetega on tegu; kes välitöödel osales ja esemekirjeldused koostas. See on oluline informatsioon uurija jaoks, kes soovib mõista kogumiskonteksti ja leida samalt välitöölt kogutud muud informatsiooni. Viimane üksikkogu, mida peakataloogis sel viisil kirjeldati, on A 850, mis on kogusse vastu võetud 1995. aastal. Peakataloog on esemeuurija jaoks eseme enese kõrval kõige olulisem infoallikas. Peakataloog on aluseks ka MuISis esemete kirje koostamisel. Praeguseks ei ole jõutud veel kaugeltki kõigi esemete kirjeid andmebaasis täita, ka ei sisalda MuIS üks ühele peakataloogi andmestikku, nii et peakataloog on uurijatele jätkuvalt oluline informatsioonikiht.

3. Andmed välitööde kohta. Väga suur osa ERMi kogudes olevatest esemetest on kogutud muuseumi korraldatud etnograafiliste välitööde käigus, kus mindi materjali koguma kindlasse piirkonda ja/või teatud teema kohta. Sel kombel toimus kogumistöö põhiosas kuni 1990. aastateni. Lisaks esemete kogumisele tehti enamasti fotosid, jooniseid ja intervjuusid, koostati välitööpäevik ja hiljem välitööde sisuline aruanne ehk etnograafiline kirjeldus. Viimastest koosneb ERMi etnograafiline arhiiv (EA). Kõik need materjalid on muuseumi käes, kuid eri tüüpi materjale säilitatakse eraldi kogudes (fotokogu, joonistekogu, käsikirjalises arhiivis on välitööpäevikud (TA) ja EAd). Kõik need võivad sisaldada esemeuurija jaoks tarvilikku teavet. Sageli leiab nendest allikatest andmeid talude ja inimeste kohta, keda välitöödel külastati ja kelle käest kogutud esemed pärinevad. Sõltuvalt uurimisküsimusest võib ka see informatsioon olla väärtuslik taustateave, mis aitab eseme valmistamis- ja kasutamiskonteksti kohta pilti luua.

4. Esimese 20 ooo eseme ehk aastatel 1909-1920 kogutud esemete kohta käiv lisateave ei ole korraldatud päris samade põhimõtete järgi kui alates 1920. aastast tehtud välitööde puhul. Välitööde aruannet EA kujul siis veel ei vormistatud, küll aga pidasid vanavara kogujad korjamisraamatuid ja välitööpäevikuid. Osa viimastest on välja antud sarjas „Vanavara kogumisretked“. Peakataloogi sissekanded on tehtud ka nende esemete kohta, kuid on hilisematega võrreldes palju napisõnalisemad. Ka leidub ERMi arhiivis nende kogumisretkede kohta mitmesugust lisateavet (täpsemalt vt Õunapuu 2011; Ütt 2015).

5. Ese on vahel muutunud ka muuseumis oldud aja jooksul. Eriti varasematel aastakümnetel on esemeid restaureeritud (versus konserveerimine tänapäeval), st katkine ese on taastatud selle (eeldataval) esialgsel kujul. Nende tööde kohta on olemas 
restaureerimisprotokollid koos kirjeldusega ja paljudel juhtudel foto enne ja pärast restaureerimist (foto 16). Mõnikord, eriti eseme valmistamistehnoloogiale keskenduva uurimise puhul, on oluline teada, kas ja mis ulatuses on eset muuseumis restaureeritud.

Foto 16

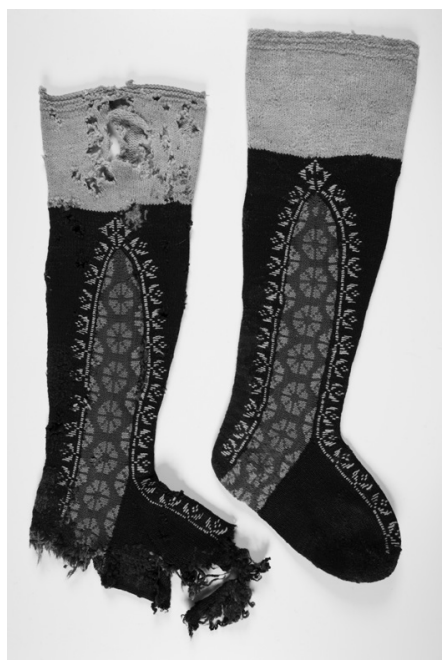

\section{Esemeuurimise teadusteoreetiline taust ja muuseumikogud}

Etnoloogia on distsipliin, mis loob eelkõige välitööde jm kogumistöö kaudu ise oma allikad. Pikka aega olid etnograafilised muuseumikogud ja teaduslik etnograafiline uurimistöö omavahel tihedalt seotud: uurimistöid kirjutati kogude põhjal ja kogusid täiendati vastavalt uurimisteemadele. Seega mõjutasid etnograafiateaduses kehtivad teooriad ja meetodid otseselt seda, mida ja kuidas muuseumi jaoks koguti.

Esimestesse suurtesse muuseumidesse Euroopas ja PõhjaAmeerikas koondusid esemekogud ja -uurimine juba 19. sajandi lõpul (Buchli 2002: 2). Tollane mõjukas kultuuriuurimise teooria oli evolutsionism. Evolutsionistid eeldasid, et kõik kultuurid läbivad sama arengutee metslusest tsivilisatsioonini. Madalaimal tasemel arvati asuvat küttimise ja korilusega tegelevad rahvad ja kõrgeimas tipus Euroopa kultuurid. Nii nagu kultuurid tervikuna, pidid progressitee lihtsamast keerukamani läbima ka üksikud kultuurinähtused, sh esemed. Seepärast oli üks evolutsionistide põhilisi meetodeid esemete jagamine tüüpideks ehk tüpoloogiate koostamine, mis kujunes mõjukaks juba 1870.-1880. aastatest alates (Hicks 2010: 30). 
Teine mõjukas teooria 19. sajandi lõpul oli difusionism. Selle kohaselt laenavad kultuurid või sotsiaal-kultuurilised piirkonnad teatud kultuurielemente üksteiselt. Kultuurilised innovatsioonid sünnivad vähestes keskustes ning levivad perifeeria suunas.

20. sajandi algul hakkas evolutsionism moest minema, kuid materiaalse kultuuri uurimine kogus tähtsust ühes teises aspektis. Kiire tööstuslik areng tõi kaasa traditsioonilise talupojakultuuri hääbumise linnastuvas ja moderniseeruvas Euroopas. Ühest küljest nostalgia, teisest küljest rahvusliku ideoloogia võidukäigu mõjul tõusis huvi omamaise kaduva talupoegliku kultuuri vastu. Mineviku kultuuriväärtused said valuutaks, mille abil rahvus sai tõendada oma tugevust, arengutaset ja väärtust (Buchli 2002: 8-9). Ka Eesti etnograafia kandev retoorika keerles n-ö vanavara päästmise ümber. Koos kultuuri muutumise kiirusega tajuti vajadust koguda kiiresti, enne kui on hilja ja möödunud aegade talupojakultuur hävib. (Eesti etnograafia ja rahvusideoloogia seostest vt pikemalt Jääts, Metslaid 2018).

1920.-1930. aastatel tekkis nn kultuuripiirkondade (culture area) koolkond, mis kasutas nii evolutsionismi kui ka difusionismi ideid, aga arendas neid uuel viisil edasi. See koolkond koondas tähelepanu kultuurinähtuste geograafilisele levikule ja kultuurilaenudele. Võeti kasutusele kartograafiline meetod - esemete jm kultuurinähtuste levikukaartide joonistamine. Kui eritüübiliste kultuurinähtuste levikupiirkonnad langesid kokku, võis olla tegu kultuuripiirkonnaga. Kultuuripiirkonna kujunemist mõjutasid looduslikud tingimused, administratiivsed piirid vms.

Kultuuripiirkondade uurimine ehk ajaloolis-geograafiline meetod saavutas Euroopa etnoloogias tohutu kõlapinna ning jäi aastakümneteks armastatuimaks meetodiks (Kõresaar 2012).

Eesti etnoloogias tõusis ajaloolis-geograafiline meetod juhtpositsioonile 1920. aastatel, püsides seal 1980. aastate lõpuni (Viires 1994: 1257; Pärdi 1995; Kõresaar 1999: 12; Leete, Tedre ja Viires 2008). ERMi esimene direktor ja Tartu Ülikooli etnograafia õppetooli dotsent Ilmari Manninen määratles 1924. aastal etnograafia kui „asjalist vanavara" uuriva teaduse. Seega uuris etnograafia kultuuri esemelist poolt ja minevikku suunatud, traditsioonilist talurahvakultuuri. Manninen pani kirja ka etnograafia põhilised uurimissuunad (1924: 531):

1. Võimalikult tervikliku ülevaate loomine Eesti materiaalsest kultuurist.

2. Tüpoloogiate loomine ja tüübi arenemise jälgimine tähtsamates esemerühmades.

3. Tähtsamate asjade ja tüübiliste teisendite geograafilise leviku väljaselgitamine ja etnograafiliste kultuuripiirkondade kindlakstegemine. 
4. Sugulussuhete määramine Eesti ja naaberrahvaste materiaalse kultuuri vahel.

Manninen võttis kultuuripiirkondade mõiste muuseumi kogumis- ja uurimistöö keskseks teljeks (Nõmmela 2009: 120). Sellest ideestikust tulenes seisukoht, et muuseumikogus võiks olla palju ühte rühma kuuluvaid esemeid, sest nii saab paremini tüübi arenemist jälgida. Samuti peeti oluliseks, et kogud oleksid geograafiliselt võimalikult ülevaatlikud; et materjali oleks igast Eesti kihelkonnast (samas: 159). Eesti ja naaberrahvaste esemelise kultuuri võrdlemise üks eesmärke oli välja selgitada, mis on oma ehk algupärane; mis laenatud ja kuidas laenud on omaksvõetuna muutunud. Siin peegeldub difusionismile omane huvi kultuurilaenude vastu (Viires 1970: 234; Annist ja Kaaristo 2013).

1950.-1960. aastatest peale kaotas kultuuripiirkondade koolkonna ideedest tõukuv esemeuurimine mõneks ajaks rahvusvahelises etnoloogias tähtsuse seoses sotsiaalantropoloogia esile kerkimisega (Tilley 2006: 2) ning teisalt traditsioonilise talupoegliku elulaadi kadumisega. Nõukogude Eesti etnograafias jäid domineerima minevikku suunatud ja eelkõige talupojakultuuriga seotud teemad. Uurimisteemade ring alates 1960. aastatest mõnevõrra laienes (linna ja kaasaja kultuuri uurimine, sotsiaal-ajaloolise ja kunstiajaloolise aspekti tugevnemine jms), kuid ERMi kogumispoliitikas ja kogutud esemete tüübistikus see kuigivõrd esile ei tõuse (nõukogudeaegsest kogumis- ja uurimistööst vt pikemalt Pärdi 1991; Leete, Tedre ja Viires 2008; Astel 2009; Konksi 2009; Jääts ja Metslaid 2018). Endiselt koguti eesmärgiga täita lüngad olemasolevate esemetüüpide variatsioonides ja geograafilises levikus, esemekogude maht kasvas kiiresti. Tollase direktori Aleksei Petersoni sõnul „... käidi kogu Eesti spetsiaalselt kogude täiendamiseks ca 15 aasta jooksul [1960.-1970. aastatel] peaaegu kaks korda üle“ (1986: 20).

1990. aastatest alates toimus Eesti etnoloogias kiire ja põhjalik pööre ajalooliselt suunitluselt nüüdisaegse ühiskonna ja lähimineviku uurimise poole, samuti võeti kasutusele uusi teoreetilisi ja metoodilisi lähenemisi (Leete jt 2008: 31; Annist ja Kaaristo 2013). Uurimistööd hakkasid üha enam tuginema otseselt selle uurimistöö tarbeks tehtud välitöödele, mitte muuseumikogudele. Ühtlasi vähenes tunduvalt esemete kasutamine teadustöö allikana ning ka välitööde käigus muuseumisse kogutud esemete hulk. Välitöödel kasutatakse viimastel aastakümnetel andmete kogumisel pigem intervjuumeetodit ning visuaalset dokumenteerimist (fotografeerimine ja filmimine).

Praegu kehtivate ERMi kogumispõhimõtete keskmes on argikultuuri kajastav aines (prioriteetsete teemadena on välja toodud näiteks elulaadi muutus alates 20. sajandi algusest kuni tänapäevani, 
kodu, institutsionaalne ja avalik sfäär, osakultuurid). Väga oluliseks hinnatakse eseme legendi, st et vastuvõetud esemega kaasneks võimalikult detailne lugu (Eesti Rahva Muuseumi kogude täiendamise põhimõtted 2015-2019: 12-15).

Esemeuurimine, sh muuseumikogude esemete uurimine on viimastel aastatel kasvanud. Uuesti on tõusnud huvi muuseumiesemete vastu, mis võimaldavad allikana uurida ühiskonna sotsiaalseid, majanduslikke või kultuurilisi suundumusi. Katsetatakse uute lähenemisviisidega, nagu eseme materiaalsus (Ingold 2013) või sotsiaalsuse ja kultuuri käsitlemine esemete valmistamise ja tegutsemise kaudu (making and doing), ühendades materiaalse kultuuri ja tehnoloogiate uurimise vaatepunkte (Vannini 2009).

\section{Eseme kirjeldamine ja analüüs}

Vaatame, millistest sammudest koosneb esemeuurimine ja mis on selle eripärad ERMi Eesti kogude puhul. All loetletud uurimisetappe tuleb võtta kui üldistavaid ja tinglikke, sest mõistagi sõltub palju konkreetsest uurimisteemast. Esemeuurimise eesmärgid võivad olla üpris erinevad alates praktilistest (nt koopia valmistamine või muu käsitöö- või kunstiprojekt) kuni teoreetiliste uurimusteni, mille teemaspekter võib samuti olla väga lai (eseme tehnilisest valmistamiskäigust või materjalist kultuuriliste tähendusteni).

Esemeanalüüsi võib jagada tinglikult nelja etappi:

1. füüsiline kirjeldus, 2. tõlgendus, 3. muuseumi- ja kogumiskonteksti andmete lisamine ja lõpuks 4. uurimisküsimuste sõnastamine, mis hõlmavad laiemat konteksti kui ese ise (siinne esemeanalüüsi meetod on kohandatud Prown 1982 põhjal). Nagu öeldud, sõltub püstitatud küsimusest, millele eset uurides rohkem tähelepanu pöörata. Mõnel juhul võib selleks olla materjal ja mõõdud, teisel juhul eseme valmistaja ja valmistamise aeg või hoopis ornament ja muud kaunistamisviisid. Seega ei pruugi kõik need analüüsietapid olla iga uurimisteema puhul võrdselt olulised. Samuti ei liigu tegelikus analüüsiprotsessis uurija mõtted, küsimused, oletused just selles järjekorras, näiteks võib eseme füüsilise kirjeldamise faasis tekkida oletusi selle vanuse või selle kohta, kas seda on kasutatud argises või pidupäevasemas kontekstis. Samuti võib loetud uurimus anda uurijale teavet, mis suunab juba tehtud füüsilist kirjeldust üle vaatama ja pöörama tähelepanu mingitele detailidele, mis olid seni vaatluse alt välja jäänud. Praktikas liigubki esemeanalüüs pigem nende etappide vahel edasi-tagasi. Samas on siiski kasulik neid etappe teadvustada, et kogunevat informatsiooni mõtetes paremini struktureerida. 


\section{Eseme füüsiline kirjeldamine}

- $\quad$ mõõdud (vajadusel kaal);

- materjal: mis materjale on kasutatud vastavalt eseme osadele; mida on rohkem, mida vähem. Mõnel juhul on oluline ka viis, kuidas materjal on saadud, nt savisegu keraamika jaoks;

- $\quad$ tehnika ja konstruktsioon: kanga puhul kas labane, toimne vm kude; puust mööblieseme puhul nt tapitüüp, kas liimitud või mitte jne;

- $\quad$ eseme välimuse, visuaalse iseloomu kirjeldus: värv, heledustumedus, tekstuur, joonte ja pindade rütm;

- kaunistused/sümbolid: ornament, dekoratiivsed motiivid, kirjad, daatumid, vapid, mis on esemele maalitud, uuristatud, graveeritud, sisse kootud jne.

Eseme füüsiliste omaduste kirjeldamiseks võib kasutada mis tahes tehnilisi vahendeid, mis tunduvad vajalikud, alates mõõdulindist kuni keerukate laborianalüüsideni. Paljude ERMi kogu esemete kohta on samade põhipunktide järgi koostatud peakataloogi sissekanne, mõnede kohta ka MuISi andmebaasi oma. Kindlasti tuleb ka nendega tutvuda. Aga kui uurimisallikaks on esemed, siis on põhjust need ise üle vaadata ja veenduda, et kogutud andmed on piisavad ja korrektsed. Mõni uurimisküsimus eeldab näiteks palju põhjalikumat füüsilist kirjeldust kui peakataloogi sissekanne, liiatigi võib viimase esemekirjeldustes esineda vigu.

\section{Tõlgendus}

Kui võimalik, katsetab uurija, kuidas ese käes tundub (mugav või mitte, pehme, kare, kõva; hoone puhul siseneb ruumi, et seda tajuda). Tööriista puhul võib ette kujutada, kuidas seda kasutati selle kunagises õiges ajaloolises kontekstis. Edasi võib aidata ka eksperimenteerimine originaali järgi valmistatud koopiaga. Mõnel juhul on kõnekas seegi, mis tunde ese tekitab (elevust, nalja, aukartust, hirmu, ebameeldivust jms). See, mida uurija pidas ainult enda isiklikuks emotsiooniks, võib olla sama ka teiste inimeste puhul. Kui paljudel inimestel tekib ühesugune reaktsioon, on see kultuuriliselt oluline ja vajab tõenäoliselt lähemat tähelepanu.

\section{Muuseumi- ja kogumiskontekst}

Siitpeale lisandub eseme enda uurimisele veidi laiem teemadering: muuseumikogude kontekst, kogumiskontekst ja muu muuseumis leiduv lisainformatsioon. Kogumiskonteksti lahtimõtestamise esimene samm on teada saada, mis asjaoludel ese muuseumisse jõudis: kas see on kogutud välitöödel; kas omanik on selle muuseumile andnud või on see mõne ettevõtte või organisatsiooni likvideerimise või ümberorganiseerimise tõttu muuseumisse antud. Kõigil juhtudel on 
uurija jaoks esmane oluline infoallikas ERMi peakataloog ning MuIS.

Nagu eespool tõdetud, on kõige rohkem esemeid jõudnud ERMi kogudesse välitööde kaudu. Välitööd on aga oma eesmärkide ja võimaluste poolest olnud erinevad, mis peegeldub ka selles, kui palju lisainformatsiooni kogutud eseme kohta võib praegu ERMi kogudes leida. Nn uurimuslikud välitööd on algatatud kindlal teemal, et koguda andmeid nimelt selle kohta ja teatud uurimisküsimustest lähtudes. Kui uuritav ese on kogutud niisuguste välitööde käigus, on uurijal kõige enam lootust saada väärtuslikku lisainformatsiooni välitöö EAst, välitööpäevikust, fotodelt või joonistelt. Näiteks Ants Viirese välitöödest Avinurme vallas 1947. aastal on ERMi kogudesse jõudnud esemed ERM A 531, fotod Fk 1089 ja Fk 1127 ning „Ülevaade kodutööndusest Avinurme vallas Jõgevamaal“, EA 54:2. Kõik need materjalid keskenduvad kodutöönduslikule puutööle kõnealuses piirkonnas. Näiteks leiame esemekogust neil välitöödel kogutud soonehöövli (A 531:14), peakataloogis on selle kohta sissekanne. EAst leiame lisainfot nii soonhöövli kasutamise kui ka kinkija Kaarel Koppeli ja tema talu kohta ning fotokogust Ants Viirese tehtud fotod Koppelist puutöid tegemas ja tema talust (Fk 1089:59-63 ja 1127:7-14).

Mahukamate sarnaste välitööde näiteks võib tuua Aravete külas 1983. aastal toimunud tööd, kust kogutud esemed on saanud seerianumbri A 70o, intervjuude teabe võtavad kokku „Materjale Aravete külast I ja II" (EA 193:2 ja EA 194:1), pildimaterjali moodustavad fotoseeriad Fk 2O29, 2030, 2037, 2038, 2039 ning joonised EJ 419. Käsikirjalises arhiivis leiduvad ka välitööpäevikud TA 785, 786, 787.

Samas ei haaku kaugeltki kõik esemekogu objektid etnograafiliste kirjelduste ehk EAdega. Nõukogude aja jooksul korraldati üldkogumisi teatud piirkonda, kus küll intervjueeriti inimesi teatud teemadel, kuid välitööde põhirõhk oli esemete kogumisel. Üldisem eesmärk oli koguda talurahvakultuuri esemeid kõigist liikidest ja Eesti piirkondadest (Peterson 1986: 23-24). Seega koguti välitöödel ka selliseid esemeid, mis antud välitööde intervjuude teemadega otseselt ei seostunud. Nii näiteks viibisid Ildike Liiv ja Tiina Võti 1958. aastal välitöödel Mustjala kihelkonnas. Intervjuude põhjal on Võti koostanud EA, mille põhiteemadeks on kaunistatud puuesemed (õllekannud, vakad ja kirstud) ning elamusisustus (toolid, lauad, voodid, hällid; EA 54:483-535). Samu teemasid kajastavad tehtud fotod (Fk 1260:101-131). Neil välitöödel kogutud esemete seas (kogu A 563) on mitmeid õllekannusid, aga ka näiteks kaks härjaiket, kiviveokelk ja tubakalõikamisnuga.

Seega on ERMi esemekogus palju esemeid, mille uurija võib leida olulist lisateavet teistest muuseumi kogudest, aga on ka palju esemeid, mille kohta ei leidu rohkem informatsiooni kui 
see, mis on peakataloogis. Kahjuks on hetkeseisuga väga raske siin täpsemat reeglipära välja tuua. Järk-järgult täieneb andmebaasis MuIS kogude materjalide seostamine (eeskätt küll selles osas, millised EAd, fotoseeriad, joonised ja välitööpäevikud on tehtud samadel välitöödel). Seoste leidmine kogutud esemete ja ülejäänud välitöömaterjalide vahel on võimalik, kuid nõuab enam süvenemist.

Saab eristada kolme perioodi, mis näitavad, mil moel ERMis välitöid tehti, ja seega on ka talletatud informatsioon erinev (vt tabel 2). Andmed tuginevad varasematele uurimustele (Peterson 1986; Pärdi 1994; Ounapuu 2011) ja ERMi peakataloogile.

Tabel 2. Eesti ala esemete kogumine ja nende kohta käiva lisainformatsiooni allikad ERMis

\begin{tabular}{|c|c|c|c|}
\hline & Välitööd 1909-1920 & Välitööd 1920-1990 & Välitööd 1990-2018 \\
\hline $\begin{array}{l}\text { Välitööde } \\
\text { tegijate ette- } \\
\text { valmistus }\end{array}$ & $\begin{array}{l}\text { Erialase ettevalmistuseta, aga } \\
\text { rahvuslikust vanavarast huvi- } \\
\text { tatud üliõpilased, kooliõpeta- } \\
\text { jad, kunstnikud, haritlased }\end{array}$ & $\begin{array}{l}\text { Etnoloogia- ja muuseumitöö } \\
\text { ettevalmistusega inimesed, et- } \\
\text { noloogia üliõpilased (erandiks } \\
\text { 1920. aastate algus, kui osales } \\
\text { veel erialase ettevalmistuseta } \\
\text { inimesi) }\end{array}$ & $\begin{array}{l}\text { Etnoloogia- ja muuseumitöö } \\
\text { ettevalmistusega inimesed, } \\
\text { etnoloogia üliōpilased }\end{array}$ \\
\hline Mida koguti & $\begin{array}{l}\text { Traditsioonilise talu- } \\
\text { rahvakultuuri kaunistatud } \\
\text { esemed ehk rahvakunst, } \\
\text { lähtuti vanavara päästmise } \\
\text { ideest }\end{array}$ & $\begin{array}{l}\text { Traditsiooniline talurahva- } \\
\text { kultuur, lähtuti vanavara } \\
\text { päästmise ideest, koguti palju } \\
\text { rahvakunsti, aga teadlikumalt } \\
\text { suhtuti argisemate esemete } \\
\text { esindatusse. } \\
\text { 196o. aastatest alates lisandus } \\
\text { linnakultuuri ja kaasaja eseme- } \\
\text { te kogumine }\end{array}$ & $\begin{array}{l}\text { Esemeid koguti välitöödel } \\
\text { vähe. Suur osa kogudesse } \\
\text { võetud esemetest on oma- } \\
\text { nike algatusel muuseumile } \\
\text { pakutud või kogutud seoses } \\
\text { mõne näituse ettevalmista- } \\
\text { misega; peamiselt nõukogu- } \\
\text { de perioodi ja kaasaja, aga ka } \\
\text { 1920.-1930. aastate esemed }\end{array}$ \\
\hline $\begin{array}{l}\text { Esemed ERMi } \\
\text { kogus }\end{array}$ & $\begin{array}{l}\text { A kogu } 20 \text { ooo esimest eset } \\
\text { (märgistus ilma A-täheta) }\end{array}$ & $\begin{array}{l}\text { Peamiselt kogu A, osalt ka } \\
\text { kultuurilooline kogu D }\end{array}$ & $\begin{array}{l}\text { Peamiselt kogu A, osalt ka } \\
\text { kultuurilooline kogu D }\end{array}$ \\
\hline $\begin{array}{l}\text { Lisainformat- } \\
\text { sioon eseme } \\
\text { kohta }\end{array}$ & $\begin{array}{ll}\text { - } & \text { Peakataloog } \\
\text { - } & \text { Korjamisraamat } \\
& \text { jogumisretkel tehtud } \\
\text { - } & \text { Poole EAd, aga on } \\
& \text { välitööpäevik (TA) }\end{array}$ & $\begin{array}{ll}\text { - } & \text { Peakataloog } \\
\text { - } & \text { Korjamisraamat } \\
& \text { Välitöödel tehtud joonised } \\
& \text { (EJ) ja fotod (Fk) } \\
\text { - } & \text { Välitööpäevik (TA) } \\
\text { - } & \text { EA } \\
\text { - } & \text { Algas filmimaterjali } \\
& \text { tegemine välitöödel (F) }\end{array}$ & $\begin{array}{ll}\text { - } & \text { Peakataloog } \\
\text { - } & \text { Korjamisraamatud kuni } \\
& \text { aastani } 2002 \\
\text { - } & \text { Fotod (Fk) } \\
\text { - } & \text { Välitööpäevik (TA) } \\
\text { - } & \text { Jooniseid (EJ) tehti ERMi } \\
& \text { korraldatud välitöödel } \\
& \text { kuni 1992. aastani } \\
\text { - } & \text { EA } \\
\text { - } & \text { Video- (V) ja filmikogu } \\
& \text { (F) } \\
\text { - } & \text { Fonoteek (Fn) }\end{array}$ \\
\hline
\end{tabular}

\section{Uurimisküsimused ja hüpoteesid}

Viimases analüüsietapis võtab uurija kokku kõik, mida ta eelmises kahes faasis nägi, tajus ja mõtles, ning otsib tähendusi ja põhjusi. Tõenäoliselt selgub siis, et on vaja leida hulk infot teistest allikatest ja kirjandusest ehk teisisõnu algab eseme konteksti uurimine vastavalt uurija probleemipüstitusele. 
Toon näite, kus uurimuse esemeliseks allikaks on muuseumi A kogus olevad toolid. Võimalik kontekst ja potentsiaalsed uurimissuunad on järgmised:

- $\quad$ Toolide valmistajad. Paljudel juhtudel on peakataloogis valmistaja nimi ja elukoht. Harvem leidub andmeid tema sotsiaalse staatuse kohta - kas ta oli taluperemees, sulane, vabadik vm. Uurimistöö selles suunas eeldab tööd arhiiviallikatega.

- $\quad$ Toolide konstruktsioonile ja stiilielementidele keskendudes huvitab uurijat kunsti- (täpsemalt mööbli-)ajalugu, import ja kaubandussidemed, nt selleks, et täpsustada, kuidas importtooted mõjutasid kohalikku mööblistiili.

- $\quad$ Tool kui sisustuselement vajab taustaks informatsiooni elumaja interjöörist, ruumidest ja nende funktsioonidest ning sellest, milline oli ülejäänud mööbel. Oluliseks võivad osutuda pere majanduslikud võimalused ja tooli rahaline väärtus.

- Kultuuriline tähendus. Siia kuuluvad rituaalsed (nt pruuditool) ja staatusobjekti seosed (nt oksjonitelt soetatud mõisamööbel); tooli tähenduse muutumine staatusobjektist argiseks esemeks; traditsioonilisusele viitava kujundusega toolid (nn eesti stiil 1920. aastatel või UKU toolid nõukogude ajal).

\section{Eseme lisainformatsioon ja allikakriitika}

Kõik eseme lisainformatsiooni liigid (peakataloog, EAd, fotod, joonised jne) alluvad omakorda allikakriitilisele uurimisele. Välitöödel käija ning peakataloogi või MuISi sissekande tegija lähtus oma teadmistest ja ajastu teadustöö normidest. Seepärast tuleb ka peakataloogis ja MuISis olevasse esemekirjeldusse või EA teksti suhtuda samasuguse allikakriitikaga kui mistahes teise kunagisse kirjalikku dokumenti.

Peakataloogi esemekirjeldus sisaldab kahte laadi informatsiooni: kataloogija koostatud kirjeldus ning eseme legend ehk informatsioon, mis pärineb viimaselt omanikult, enne kui ese muuseumisse jõudis. Sageli sisaldab viimane teavet eseme vanuse, otstarbe, valmistamise või kasutamise kohta. Legend on kõige vahetum teave, mis jõuab meieni eseme muuseumieelsest elust, selle varasemalt omanikult ning aitab selle kultuurikonteksti rekonstrueerimisel väga palju edasi. Teisest küljest ei saa legendi pimesi usaldada. Sageli leiab peakataloogist märkuse, et ese on „umbes 50/100/150 aastat vana“, enamasti puudutab see $n$-ö traditsioonilise rahvakultuuri esemeid (rahvariided, ehted, tööriistad). Siin tuleb tähele panna, mis aastal on ese kogutud, muuseumisse toodud. Umbkaudne vanus tuleb lahutada sellest aastast. Näiteks on ese kogutud 1924. aastal ja omanik on hinnanud 
selle vanuseks umbes 100 aastat, seega võiks ese olla valmistatud 1820. aastatel. Selline hinnanguline vanus eseme legendis tähendab, et inimene, kellelt ese välitöödel saadi, on pakkunud selle välja oma mälu järgi. Oletame, et omanik oli sel hetkel 75 -aastane ja ta mäletas oma vanemate jutust, et ese oli olemas juba enne tema sündi. Rohkemat ei ole eseme vanusest teada, seega on antud hinnanguks „umbes 100 aastat". Nii mõnigi kord ei ole see hinnang kuigi täpne ja tegu võib olla palju vanema või hoopis noorema esemega. Kui uurimistöö seisukohalt on eseme vanuse määramine oluline, siis tasub sellesse hinnangusse suhtuda reservatsioonidega ja püüda hinnata vanust ka muul viisil. Paljude esemete puhul annab vihjeid valmistamistehnoloogia, materjal, kaunistusviis. Näiteks leiame kogust aastal 1920 kogutud puuvillase naiste tuttmütsi, millel on sees hõredast puuvillasest riidest vooder (A 19:5). Legend on selline: „Üleandja vanaema oma. Vanus 180 aastat“, samas on lähemal vaatlusel selge, et müts on masinal kootud ja ei saa kuidagi pärineda 1740. aastatest, nagu viidatakse.

\section{Kui hästi esindavad muuseumikogud argikeskkonda?}

ERMi esimene direktor Ilmari Manninen sõnastas kogumispoliitilise eesmärgi: luua võimalikult terviklikud, ammendavad kogud nii esemetüüpide kui ka Eesti geograafiliste piirkondade lõikes (1924). Nõukogude ajal jätkas sama põhimõtet direktor Aleksei Peterson (1986). Tolleaegse kogumistöö prioriteetidest lähtuvalt joonistuvad välja teemaderingid, mis on ERMi esemekogudes hästi esindatud, ja teised, mis on jäänud nõrgemaks. Heiki Pärdi on oma analüüsis (mis puudutab eeskätt talurahvakultuuri esemeid) välja toonud järgmised punktid (1994: 16-17):

- Koguti ühe ühiskonnakihi (seisuse) ehk talupoegade esemeid. Samas on vähe teada talupojaseisuse sotsiaalsest jaotumisest: kas ese kuulus jõukale või vaesele talule, peremehe või sulase perele, mõisateenijale või käsitöölisele. Hoopis pistelisemalt on teiste ühiskonnakihtide, näiteks aadlike, linnaelanike, haritlaste esemeid.

- Koguti pidupäevasemaid, kaunistatud asju, nn rahvakunsti.

See kehtib eriti Esimese maailmasõja eelse perioodi kohta, aga ei kadunud hiljemgi. Nii on meie teadmised argisest tarbevarast vastavalt tagasihoidlikumad.

- Eesti kihelkonnad ei ole kaugeltki võrdselt ERMi kogudes esindatud. Aegade jooksul on olnud välitööde tegemisel oma lemmikpiirkonnad, kus käidi korduvalt ja koguti palju esemeid, ning teisi, kus on käidud korra või paar. 
Iseäranis viimaste puhul kerkib küsimus, kas teatud esemete puudumine viitab sellele, et neid ei olnudki antud kihelkonnas, või sellele, et neid pole lihtsalt kogutud.

20. sajandi algul, mil esemeid muuseumile koguma hakati, oli Eesti ühiskond juba moderniseerumas. Taluinimeste argielus oli toimunud muutusi, piirkonniti hoogsamalt, teisal aeglasemalt, juba mitmekümne aasta jooksul, hõlmates riietust, tarbevara, kodusisustust jm. Juba kõige varasemate vanavarakorjajate päevikuist võib lugeda, et traditsioonilise talurahvakultuuri esemeid polnud paiguti sugugi lihtne leida, näiteks Paul Keerdo kirjutab 1914. aastal Harju-Madise kihelkonnast: „Rahvariided olid kõik pääle naiste mütside, mida kolm vana eite kirikus käies kandsid, tarvituselt kadunud“ (Vanavara kogumisretkedelt 10: 72). 1909. aastal Iisaku kihelkonnas esemeid kogumas käinud Eduard Pedak mainib, et Tudulinna piirkonna taludes leidus väga vähe vanavara: „Miks mitte kolmkümmend aastat varem ei korjatud, küsitakse igal pool“ (Vanavara kogumisretkedelt 3: 50). Otsitav talurahvakultuur oli teisisõnu juba siis ühiskonnas marginaalne ja muuseumisse kogutu ei kirjelda 20. sajandi alguse keskmist Eesti külaelu (rääkimata linnadest). Samas võib ka küsida, kui hästi esindavad muuseumikogud aastakümneid varasemat traditsioonilist külaelu, sest koguti seda, mis oli hiljem säilinud.

Paljud kuni 1930. aastateni kogutud esemed ei olnud kogumise ajal vanemad kui 20-30 aastat, mitmel oli vanust ka vähem kui 10 aastat. Tänapäeva mõistes on see kaasaja või lähimineviku kultuuri esemete kogumine. Pitseri vajutas kogutule just ideoloogiline raamistik: tollal koguti neid esemeid kui muistse, arhailise talurahvakultuuri näidiseid, olgugi et konkreetne ese võis olla valmistatud kõigest mõni aasta varem. Tänapäevase uurija jaoks rõhutab nende esemete arhailisust ka muuseumikontekst: nad kuuluvad muuseumikogude kõige vanemasse kihistusse, osalt Esimese maailmasõja eelsesse kogumisperioodi. Aga see ei pruugi tähenda, et ese esindaks tingimata sajandipikkuseid talupoeglikke traditsioone. 19. sajandi lõpukümnendid ja sajandi algusaastad olid Eestis vägagi dünaamilised, mil mood, materjal ja ostukaup olid ka maarahvale kättesaadavamad kui kunagi varem.

\section{Tegelikkuse rekonstrueerimine}

Muuseumisse kogutud esemed on ainult üksikud fragmendid kunagi olemas olnud füüsilisest argikeskkonnast. Suure osa tervikpildist loob uurija oma mõtetes eseme ümber ise, toetudes teistele allikatele ja varasematele uurimustele. Aeg-ajalt on hea värske pilguga oma 
uurimismaterjal üle vaadata ja täpsustada, mida saab allika alusel tõestada ja kust alates toetume oma järeldustes ehk juba aastakümneid kirjanduses tiirelnud tõlgendustele ja rekonstruktsioonidele. Näiteks on kihelkondlikud rahvarõivakomplektid sellisena, nagu me neid tunneme rahvarõivaste üldkäsitluste kaudu (nt Kurrik 1938; Eesti rahvarõivaid 1957; Kaarma ja Voolmaa 1981), loonud peamiselt rahvarõivauurijad. Muuseumikogudes on küll arvukalt üksikuid rahvarõivaelemente (seelikuid, särke jne), kuid üliharva on kogutud terve riietuskomplekt samalt inimeselt, nii et saab kindlalt väita, et just sellist seelikut, särki, peakatet ja jalanõusid kandis üks inimene komplektina koos. Rahvarõiva üldkäsitlustes välja pakutud kihelkondlikud komplektid sisaldavad juba uurimuste autorite valikuid ja üldistusi ning ei peegelda muuseumikogudesse talletatut kogu selle varieeruvuses (vt nt Viires 1990; Piiri 1992; Värv 2008; Nõmmela 2010; Raud 2014; Loite 2015; Rannap 2018).

Mõneti sarnane probleem tekib vanemat tüüpi talumööbliga: muuseumis on ohtralt üksikuid mööbliesemeid (toolid, lauad, kapid, voodid jne), millest mõned on valmistatud 19. sajandi keskpaiku ja varem. 19. sajandi viimasest veerandist alates on eluruumide sisevaadete fotosid ning 20. sajandi algusest etnograafilisi jooniseid rehemajade interjöörist (Habicht 1977). Seega on vähe kindlaid andmeid talu eluruumide, eriti kambrite mööbli ning selle paigutuse kohta 19. sajandi jooksul ja lihtne on omistada aastakümneid hilisema pildimaterjali interjöörivaateid varasemale perioodile.

Kindlasti ei ole sellises ajaloolise keskkonna rekonstrueerimistöös midagi halba, pigem on see möödapääsmatu. Oluline on aga olla teadlik, kust uurija tõlgendus algab ja mis on allika järgi tõendatav.

\section{Kokkuvõte}

Inimese valmistatud esemed on kultuuri osa. Ükskõik mis aspektist vaadata - nende materjalist ja valmistamisest kuni rituaalse kasutamise ja tähenduseni -, on esemete maailm tihedalt põimunud tehnoloogiliste, sotsiaalsete, majanduslike, religioossete jt valdkondadega.

Ese võib olla väärtuslik uurimisallikas nii mineviku kui ka tänapäeva kultuuri uurija jaoks. Kuivõrd mineviku kultuurist pärinevad esemed koonduvad muuseumikogudesse, tekib uurijal mitmesuguseid küsimusi seoses eseme kui allikaga: nii üksiku eseme kirjeldamise ja analüüsi tasandil kui ka laiemalt, muuseumikogu tasandil. Muuseumi esemekogu ei ole neutraalne ja objektiivne päris elu representatsioon. 
Samuti ei ole neutraalne ja objektiivne elu representatsioon ükski teine etnograafiline allikas, mida ERMi kogudes säilitatakse. Välitööpäevikud, aruanded, fotod, esemekirjeldused ja -kogud peegeldavad oma ajastu teadusteoreetilisi seisukohti, arusaamu sellest, mis on etnograafia/ etnoloogia ja ERMi ülesanne. Allikakriitika peab alati arvestama tausta, esemeuurimise puhul kuulub selle alla ka muuseumikontekst.

\section{LIISI JÄÄTS (MA) on Eesti Rahva Muuseumi kuraator. Tema 2010. aastal kaitstud magistritöö teemaks oli nüüdisaja maaelu mõjutavad ideoloogiad ja väärtushinnangud, mh kultuuripärandi valdkonnas. Uurimishuvid on seotud kultuuripärandi representatsiooni ja materiaalse kultuuri uurimisega.}

\begin{abstract}
Allikad
Eesti Rahva Muuseumi kogude korralduse põhimõtted 2015-2019.
\end{abstract}

\section{Kirjandus}

Annist, Aet; Kaaristo Maarja. 2013. Studying home fields: encounters of ethnology and anthropology in Estonia. - Journal of Baltic Studies 44 (2): 121-151.

Astel, Eevi. 2009. Eesti Rahva Muuseum aastatel 1940-1957. - Eesti Rahva Muuseumi 100 aastat. Tartu: Eesti Rahva Muuseum, 186-247.

Buchli, Victor. 2002. Introduction. - The Material Culture Reader. Toim Victor Buchli. Oxford, New York: Berg, 1-22.

Eesti rahvarõivaid $1957=$ Eesti rahvarõivaid XIX sajandist ja XX sajandi algult. (toimetuskolleegium Harri Moora jt). Tallinn: Eesti Riiklik Kirjastus.

Habicht, Tamara. 1977. Rahvapärane arhitektuur. Tallinn: Kunst.

Hicks, Dan. 2010. The material-cultural turn. Event and effect. - The Oxford Handbook of Material Culture Studies. Ed by Dan Hicks and Mary C. Beaudry. Oxford: Oxford University Press, 24-98.
Eesti NSV Etnograafiamuuseumi restaureerimisprotokoll nr 66, 1966.

Ingold, Tim. 2013. Materjalid materiaalsuse vastu. Studia Vernacula 4: 39-57.

Jääts, Indrek; Metslaid, Marleen. 2018. Eesti etnograafia ja eesti rahvuslus. - Keel ja Kirjandus 1-2: $118-135$.

Kaarma, Melanie; Voolmaa, Aino. 1981 (parandatud trükk 2015). Eesti rahvarõivad. Tallinn: Eesti Raamat.

Kaarma, Melanie; Voolmaa, Aino. 2015. Eesti rahvarõivad. Tartu: Eesti Rahva Muuseum.

Kirschenblatt-Gimblett, Barbara. 1991. Objects of ethnography. - Exhibiting Cultures: the Poetics and Politics of Museum Display. Toim Ivan Karp ja Steven Lavine. Washington: Smithsonian Institution Press: 386-443.

Konksi, Karin. 2009. Etnograafiamuuseumina Nõukogude Eestis 1957-1991. - Eesti Rahva Muuseumi 100 aastat. Tartu: Eesti Rahva Muuseum, 250-355.

Kurrik, Helmi. 1938. Eesti rahvarõivad. Tartu: Eesti Rahva Muuseum. 
Kõresaar, Ene. 1999. Vaip - tekki muodi asi. Etnoloogiline esemeuurimus. Studia Ethnologica Tartuensia 2. Tartu: Tartu Ülikool, etnoloogia õppetool.

Kõresaar, Ene. 2012. Allika mõistest ja mõistmisest. Kursuse Etnograafilised allikad õppematerjal. http://dspace.ut.ee/bitstream/handle/10062/28638/Etnograafilised_allikad_materjalid.pdf

Leete, Art; Tedre, Ülo; Viires, Ants. 2008. Uurimislugu. - Eesti rahvakultuur. Toim Ants Viires ja Elle Vunder. Tallinn: Eesti Entsüklopeediakirjastus, 15-39.

Loite, Kersti. 2015. Üksikesemest ülikonnani Virumaa rahvarõiva näitel. - Studia Vernacula 6: $42-63$.

Manninen, Ilmari. 1924. Etnograafia tegevuspiiridest ja sihtidest Eestis. - Eesti Kirjandus 12: 527-537.

Nõmmela, Marleen. 2009. Rahvusmuuseum rahvusriigis. - Eesti Rahva Muuseumi 100 aastat. Tartu: Eesti Rahva Muuseum, 104-171.

Nõmmela, Marleen. 2010. The state, the museum and the ethnographer in constructing national heritage: Defining Estonian national costumes in the 1930s. - JEF. Journal of Ethnology and Folkloristics 4 (1): 49-61.

Olsen, Björnar. 2017. Asjade tagasivõitmine: mateeria arheoloogia. - Vikerkaar 1-2: 75-90.

Peterson, Aleksei. 1986. Varaait. Ülevaade etnograafiamuuseumi ajaloost ja kogudest. Tallinn: Valgus.

Piiri, Reet. 1992. Rahvarõivas esinemisrõivana. Eesti Rahva Muuseumi aastaraamat XXXIX: 116-131.

Prown, Jules David. 1982. Mind in matter: An introduction to material culture theory and method. - Winterthur Portfolio 17 (1): 1-19.

Pärdi, Heiki. 1991. Kriitilise pilguga Eesti Rahva Muuseumi esemekogumise poliitikast. - Keel ja Kirjandus 9: 561-566.

Pärdi, Heiki. 1994. Eesti Rahva Muuseumi kodumaised esemekogud. 'Ethnographica' paikkondlik päritolu. - Eesti Rahva Muuseumi aastaraamat XL: $11-59$.

Pärdi, Heiki. 1995. Muuseum - kultuurinähtus ja kultuuriuurimise allikas. Magistritöö. Tartu.
Rannap, Mareli. 2018. Paikkondliku rahvarõivanõuandekoja tegevuspõhimõtted. Saaremaa nõuandekoja näide. Magistritöö. https://dspace.ut.ee/handle/10062/60378

Raud, Inna. 2014. Vändra kihelkonna naiste traditsioonilised rahvarõivad: komplektide koostamine ja valmistamine tänapäeval. Magistritöö. https://dspace.ut.ee/handle/10062/41679

Tilley, Christopher; Keane, Webb; Küchler, Susanne; Rowlands, Michael; Spyer, Patricia. 2006. Introduction. - Handbook of Material Culture. (Toim Tilley, Christopher; Keane, Webb; Küchler, Susanne; Rowlands, Michael ja Spyer, Patricia). London: SAGE Publications, Thousand Oaks, New Dehli, 1-6.

Vanavara kogumisretkedelt 3 = Nikolai Triik. Eduard Pedak. Vanavara kogumisretkedelt 3. 2007. Koost Piret Õunapuu. Tartu: Eesti Rahva Muuseum.

Vanavara kogumisretkedelt $10=$ Paul Keerdo. Vanavara kogumisretkedelt 10. 2013 Koost Piret Õunapuu. Tartu: Eesti Rahva Muuseum.

Vannini, Phillip. 2009. Introduction. - Material Culture and Technology in Everyday Life. Ethnographic approaches. Toim Phillip Vannini. Peter Lang Publishing: New York, Washington DC/Baltimore, Bern, Frankfurt am Main, Berlin, Brussels, Vienna, Oxford, 1-12.

Viires, Ants. 1970. Etnograafilise mõtte arengu põhijooni. - Leninlik etapp Eesti ajalooteaduses. Historiograafilisi artikleid. Koost ja toim Endel Laul. Tallinn: Eesti Raamat, 231-251.

Viires, Ants. 1990. Eesti rahvarõivaste uurimise tulemusi ja probleeme. - Akadeemia 6 : 1260-1270.

Viires, Ants. 1994. Ilmari Mannineni teoreetilistest vaadetest. - Looming 9: 1255-1263.

Värv, Ellen. 2008. Riietumine ja rahvarõivad. - Eesti rahvakultuur. Ants Viires, Elle Vunder (koost ja toim). (Teine täiendatud trükk.) Tallinn: Eesti Entsüklopeediakirjastus, 279-301.

Õunapuu, Piret. 2011. Eesti Rahva Muuseumi loomine ja väljakujunemine. Tartu: Tartu Ülikooli Kirjastus. Doktoritöö. https://dspace.ut.ee/ handle/10062/18181.

Ütt, Kristi. 2015. Eesti Rahva Muuseumile aastatel 1909-1923 saadetud poolametlikud kirjad ajalooallikatena. Magistritöö. https://dspace. ut.ee/handle/10062/48578. 
Liisi Jääts

Human artifacts are part of a culture. Whatever aspect we consider - their material, manufacture, ritual use or meaning - the world of humanmade objects is closely intertwined with technological, social, economic, religious and other fields.

An artifact can be a valuable source of study for a scholar delving into either the past or contemporary culture. Insofar as objects from past cultures are concentrated in museum collections, several questions arise in the mind of a researcher regarding the object as a source material: both at the level of describing and analysing an individual item and more broadly, at the level of the museum collection. A museum's collection of artifacts is not a neutral and objective representation of real life. Nor is any other ethnographic source preserved in our museum's collections a neutral and objective representation of life. Field diaries, reports, photographs, descriptions of objects and collections reflect the theoretical views of the times, or the understanding of the mission of ethnography/ethnology and the Estonian National Museum. Source criticism must always take into account the background, which in the case of object research will also involve the museum context. 
Резюме:

\section{Фонды и анализ экспонатов Эстонского национального музея}

Лийзи Яатс

Предметы, изготовленные человеком, являются частью культуры. Независимо от аспекта рассмотрения - от материала и процесса изготовления до ритуального использования и смыслов, - мир вещей тесно переплетён с технологиями, экономикой, религиями, социальными и прочими областями.

Вещь может быть ценным источником как для исследователя прошлого, так и сегодняшней культуры. Предметы культуры прошлого собираются в музейных фондах, и у исследователя возникают вопросы по поводу них как источника: как на уровне описания и анализа отдельных предметов, так и шире, на уровне фондов.
Музейные фонды не являются нейтральной и объективной репрезентацией действительной жизни, как не является нейтральной и объективной репрезентацией ни один другой этнографический источник, хранящийся в фондах Эстонского национального музея. Экспедиционные дневники, отчёты, фотографии, описания и собрания предметов отражают научно-теоретические взгляды своего времени, представления о том, что есть этнография/ этнология и в чём заключается задача Эстонского национального музея. Критика источников всегда должна принимать в расчёт общие сведения, к которым также относится музейный контекст. 